\title{
Is serum apelin related to portal hemodynamics in patients with liver cirrhosis?
}

\author{
Ashraf G. Dala ${ }^{\mathrm{a}}$, Osama M. Ebied ${ }^{\mathrm{b}}$, Gamal Y. Abo-Raia ${ }^{\mathrm{c}}$
}

Departments of anternal Medicine, 'biagnostic Radiology, Faculty of Medicine, 'Department of Clinical Pathology, National Liver Institute, Menoufia University, Menoufia, Egypt

Correspondence to Ashraf G. Dala, MD Department of Internal Medicine, Faculty of Medicine, Menoufia University, Menoufia, Egypt. Tel: 0020483446375;

fax: 00201062855295;

e-mail: drashrafgharieb@yahoo.com

Received 27 September 2017

Accepted 20 November 2017

The Egyptian Journal of Internal Medicine 2018, 30:8-12

\begin{abstract}
Background
Apelin is the endogenous ligand of the angiotensin-like receptor. The expression of apelin-APJ (apelin receptor) signaling is associated with the development of portal hypertension $(\mathrm{PH})$ and contributes toward the formation of Porto systemic collaterals and splanchnic neovascularization in $\mathrm{PH}$.
\end{abstract}

Aims

We aimed to study the relationship between apelin and portal hemodynamics in cirrhotic patients.

\section{Patients and methods}

Thus study included 60 cirrhotic patients from Menoufia University Hospitals (Egypt) and 20 healthy volunteers as a control group. Participants underwent a physical examination and laboratory investigations [complete blood count, urea, creatinine, alanine transaminase, aspartate transaminase (AST), serum albumin, bilirubin, international normalized ratio, hepatitis $C$ virus antibody, hepatitis $B$ virus antigen, hepatitis $C$ virus PCR, alpha feto protein (AFP), and serum level of apelin]. Abdominal ultrasonographic studies of portal vein diameter, splenic size, and portal hemodynamics were carried out for all participants. Child-Pugh score, model for end-stage liver disease score, and AST/platelet (PLT) index were calculated for all participants.

\section{Results}

Serum apelin was highly significantly elevated in cirrhotics than in controls, with a $P$ value of 0.001 . Serum apelin was significantly correlated to some laboratory parameters in cirrhotics such as PLT count, alanine transaminase, AST, $\gamma$-glutamyl transferase, and bilirubin, with $P$ value less than 0.05 . There was a positive correlation between serum apelin level and the degree of liver fibrosis estimated by the AST/PLT index. Serum apelin was significantly correlated to portal vein diameter and portal flow velocity, with a $P$ value less than 0.05 , and highly significantly correlated to splenomegaly, with a $P$ value of 0.001 . The optimal cut-off point of serum apelin for the prediction of $\mathrm{PH}$ in cirrhotics is $2550 \mathrm{ng} / \mathrm{dl}$, with a sensitivity of $89 \%$, a specificity of $65 \%$, and an accuracy of $81 \%$.

\section{Conclusion}

Serum apelin is elevated in patients with cirrhosis and $\mathrm{PH}$, and a positive correlation is found between serum apelin and the degree of hepatic fibrosis. Measurement of serum apelin represents a rapid, noninvasive method for the prediction of $\mathrm{PH}$ in cirrhotics and can assess the degree of hepatic fibrosis.

\section{Keywords:}

apelin, cirrhosis, portal hemodynamics

Egypt J Intern Med 30:8-12

(c) 2018 The Egyptian Journal of Internal Medicine 1110-7782

\section{Introduction}

Portal hypertension (PH) is a hemodynamic outcome of liver cirrhosis in western countries. It causes severe alterations responsible for the onset of complications of cirrhosis. Hemodynamic alterations of $\mathrm{PH}$ involve portal-hepatic hemodynamics and also involve splanchnic and systemic circulation [1].

Apelin is a peptide isolated from bovine stomach extracts acts as an endogenous ligand for previously orphaned $G$ protein-coupled receptors (APJ receptor). Now, putative receptor protein related to the type- 1 angiotensin receptor [2]. Apelin receptors are expressed in vascular endothelial cells during early embryogenesis and apelin in combination with vascular endothelial growth factor, leading to angiogenesis through induction of the proliferation of endothelial cells and the formation of new blood vessels $[3,4]$.

Expression of endogenous apelin-APJ (apelin receptor) signaling is associated with the development of $\mathrm{PH}$, and

This is an open access article distributed under the terms of the Creative Commons Attribution-NonCommercial-ShareAlike 3.0 License, which allows others to remix, tweak, and build upon the work noncommercially, as long as the author is credited and the new creations are licensed under the identical terms. 
contributes toward the formation of porto systemic collaterals and splanchnic neovascularization in $\mathrm{PH}$ rats [5]. Apelin signaling has been known to contribute toward angiogenesis [6]; thus, apelin and its receptor APJ are essential for any embryonic angiogenesis $[4,7,8]$ and are needed for retinal vessels' formation [3,9-12]. Furthermore, apelin pitch angiogenesisin vivo and in vitro [4,11-14]. Principe et al. [15] had shown that the endogenous apelin system could be involved in intrahepatic remodeling in cirrhotic rats. Thus, apelin signaling could represent a future therapeutic target during any pathological neovascularization associated with $\mathrm{PH}[16]$.

The role of apelin in the pathogenesis of liver cirrhosis is complex as described in a report linking apelin to the initiation and maintenance of the inflammatory and fibrogenic processes occurring in liver fibrosis [17] as well as the hemodynamic and vascular abnormalities in liver cirrhosis and its complications $[15,18]$. However, there are limited clinical data showing the role of apelin in liver cirrhosis, as reported by Bertolani and Marra [19]. Therefore, highlighting the apelin system would present a potential therapeutic target for liver disease. Thus, this study aimed to determine whether there is a relation between serum apelin and portal hemodynamics in liver cirrhosis.

\section{Patients and methods}

This study included 60 patients with liver cirrhosis and 20 healthy volunteers as a control group from Menoufia University Hospitals and the National Liver Institute in Menoufia University (Egypt) in the period from April 2014 to April 2015. They underwent physical examination and laboratory investigations such as complete blood count, urea, creatinine, liver profile [alanine transaminase (ALT), aspartate transaminase (AST), serum albumin, bilirubin, international normalized ratio (INR)], hepatitis C virus antibody, hepatitis B virus antigen, $\mathrm{PCR}$ for hepatitis $\mathrm{C}$ virus $\mathrm{RNA}$, alpha feto protein (AFP), and serum level of apelin. Abdominal ultrasonographic studies of portal vein diameter, splenic size, and portal hemodynamics were carried out for all participants. Child-Pugh score, model for end-stage liver disease score, and the AST/PLT index were calculated for all patients. The exclusion criteria were as follows: patients with hypertension, diabetes mellitus, alcoholics, cardiopulmonary disorders, hepatocellular carcinoma, renal disorders, and smokers.

\section{Approval}

The Menoufia Faculty of Medicine Committee for Medical Research Ethics reviewed and formally approved the study before it was started and a written consent was obtained from all participants of the study.

\section{Statistical analysis}

The data collected were tabulated and analyzed using the SPSS statistical package version 11 (SPSS, version 11; SPSS Inc., Chicago, Illinois, USA) on IBM compatible computer. Descriptive statistics was presented as mean $\pm \mathrm{SD}$, and number and percentage and analyzed using the $\chi^{2}$-test. Student's $t$-test was used to compare two groups of normally distributed variables; the Mann-Whitney $U$-test, the correlation co-efficient test ( $r$-test), and regression analysis were also carried out whenever appropriate. Results were considered significant at a $P$ value of less than 0.05 and highly significant at a $P$ value of less than 0.001 .

\section{Results}

Apelin level was highly significantly increased in cirrhotic patients than in controls, with a $P$ value of 0.001 as shown in Table 1 .

Apelin level was significantly correlated to some laboratory parameters in cirrhotic patients such as platelet (PLT) count, ALT, AST, $\gamma$-glutamyl transferase, and bilirubin, with a $P$ value of less than 0.05 as shown in Table 2 .

Apelin level was significantly correlated to portal vein diameter and portal flow velocity, with a $P$ value of less than 0.05 , and highly significantly correlated to splenomegaly, with a $P$ value of 0.001 , as shown in Table 3 .

There was a positive correlation between serum apelin level and degree of liver fibrosis estimated by the AST/PLT index as shown in Table 4.

The optimal cut-off point of serum apelin in cirrhotic patients for the prediction of $\mathrm{PH}$ is $2550 \mathrm{ng} / \mathrm{dl}$ with a sensitivity of $89 \%$, a specificity of $65 \%$, and an accuracy of $81 \%$ as shown in Table 5 .

Table 1 Comparison between the groups studied in apelin levels $(n=80)$

\begin{tabular}{lcccc}
\hline & $\begin{array}{c}\text { Cirrhotic group } \\
(n=60)(\text { mean } \pm \text { SD })\end{array}$ & $\begin{array}{c}\text { Control } \\
\text { group }(n=20) \\
(\operatorname{mean} \pm \text { SD })\end{array}$ & $\begin{array}{c}U \\
\text { test }\end{array}$ & $\begin{array}{c}P \\
\text { value }\end{array}$ \\
\hline Age & $52.2 \pm 6.4$ & $48.7 \pm 10.4$ & 0.22 & 0.07 \\
Sex & & & & \\
Male & $41(8)$ & $11(55)$ & 0.11 & 0.3 \\
Female & $19(32)$ & $9(45)$ & & \\
$\begin{array}{c}\text { Apelin } \\
\text { (ng/dl) }\end{array}$ & $4524.35 \pm 3642.16$ & 2164.99 & 4.68 & $0.001^{* *}$ \\
\hline
\end{tabular}

*Highly significant. 
Table 2 Correlation between apelin and laboratory parameters in the cirrhotic group

\begin{tabular}{|c|c|c|}
\hline \multirow[t]{2}{*}{ Laboratory parameters } & \multicolumn{2}{|c|}{ Apelin } \\
\hline & $r$ & $P$ value \\
\hline Hemoglobin (g/dl) & 0.03 & 0.81 \\
\hline WBCs $\left(\mathrm{cell} / \mathrm{cm}^{3} \times 10^{3}\right)$ & 0.11 & 0.31 \\
\hline Platelets $\left(\mathrm{cell} / \mathrm{cm}^{3} \times 10^{3}\right)$ & +0.31 & $0.004^{*}$ \\
\hline Alanine transaminase (IU/I) & +0.22 & $0.04^{*}$ \\
\hline Aspartate transaminase (IU/I) & +0.41 & $0.001^{\star *}$ \\
\hline GGT (IU/I) & +0.22 & $0.04^{*}$ \\
\hline Albumin (g/dl) & +0.04 & 0.67 \\
\hline Bilirubin (mg/dl) & +0.28 & $0.01^{*}$ \\
\hline INR & 0.01 & 0.92 \\
\hline Urea $(\mathrm{mg} / \mathrm{dl})$ & 0.03 & 0.71 \\
\hline Creatinine (mg/dl) & 0.02 & 0.81 \\
\hline
\end{tabular}

GGT, $\gamma$-glutamyl transferase; INR, international normalized ratio; WBC, white blood cells. *Significant. **Highly significant.

Table 3 Correlation between apelin and ultrasound parameters in the cirrhotic group

\begin{tabular}{lcc}
\hline U/S parameters & \multicolumn{2}{c}{ Apelin } \\
\cline { 2 - 3 } & $r$ & $P$ value \\
\hline Portal vein diameter $(\mathrm{mm})$ & +0.22 & $0.04^{*}$ \\
Portal flow velocity $(\mathrm{cm} / \mathrm{s})$ & +0.28 & $0.01^{*}$ \\
Splenic size $(\mathrm{cm})$ & +0.41 & $0.001^{* *}$ \\
\hline
\end{tabular}

U/S, ultrasound. *Significant. **Highly significant.

Table 4 Correlation between apelin and the aspartate transaminase/platelet index, child score, and model for endstage liver disease score in the cirrhotic group

\begin{tabular}{lcc}
\hline Parameters & \multicolumn{2}{c}{ Apelin } \\
\cline { 2 - 3 } & $r$ & $P$ value \\
\hline AST/PLT index & +0.39 & $0.001^{* *}$ \\
Child score & 0.12 & 0.36 \\
MELD score & -0.13 & 0.34 \\
\hline
\end{tabular}

AST, aspartate transaminase; MELD, model for end-stage liver disease; PLT, platelet. **Highly significant.

Table 5 Validity of serum apelin for the prediction of portal hypertension

\begin{tabular}{lccc}
\hline Optimal cut-off point & Sensitivity & Specificity & Accuracy \\
\hline 2550 & $89 \%$ & $65 \%$ & $81 \%$ \\
\hline
\end{tabular}

\section{Discussion}

Chronic liver disease (CLD) including cirrhosis can be induced by various etiologies, such as hepatitis viruses, alcohol, autoimmune, or metabolic causes. Through these stimulation and inflammatory injuries, intrahepatic fibrotic change occurs and is followed by intrahepatic vascular changes, angiogenesis, and development of $\mathrm{PH}[20]$.

Some emerging studies have pointed to the possible effects of the apelinergic system in the liver and related it to inflammation [21], fibrosis [17]], angiogenesis as well as vascular and hemodynamic disturbances $[15,18]$. Other emerging studies speculated that activated hepatic stellate cells represent a potential source for hepatic apelin [15]] and that apelin contributes toward the proliferation of hepatic stellate cells induced by PLT-derived growth factors in vitro [18]. Furthermore, apelin could be an essential mediator of the profibrogenic gene induction that markedly initiates collagen-I synthesis [17], all of which are known to contribute largely toward deposition of extracellular matrix and progression of fibrosis [22,23]. Melgar-Lesmes et al. [17] pointed to the decrease in apelin expression induced by tumor necrosis factor- $\alpha$ in hematopoietic stem cell cultures and explained that it could represent a homeostatic protective response toward reducing the overactivated hepatic apelin system in advanced cirrhosis. These findings point to the possible role of apelin in CLD progression. In addition, this provides a rationale to investigate new drugs targeting the apelin-APJ signaling pathway to reduce fibrosis and to improve hemodynamics in these patients.

In the present study, the mean value of serum apelin was significantly higher in cirrhotic patients than in the control group. This result is in line with previous studies of Lim et al. [20], Principe et al. [15], and El-Mesallamy et al. [24], who reported that patients with cirrhosis showed a significant increase in apelin circulating levels than normal participants.

Another finding of the present study is the increased serum apelin level in patients with cirrhosis and $\mathrm{PH}$ and this is in agreement with Tiani et al. [5], who suggested that the expression of endogenous apelin-APJ signaling is associated with the development of $\mathrm{PH}$ and contributes toward the formation of Porto systemic collateral blood vessels and splanchnic neovascularization in $\mathrm{PH}$ rats. Moreover, Lim et al. [20] reported that serum apelin showed an increase with an increase in portal pressure. Yokomori et al. [18] reported that apelin protein and mRNA were overexpressed in human cirrhotic liver compared with normal liver, and the magnitude increased as cirrhosis progressed from early to advanced stage. In early-stage cirrhotic liver, apelin expression was increased in hepatic sinusoidal endothelial cells and in proliferated arterial capillaries directly connecting to the sinusoids. In end-stage cirrhosis, apelin was strongly expressed in proliferated arterial capillaries. These findings suggest a role of apelin in the capillarization of hepatic sinusoid and the proliferation of arterial capillaries in cirrhosis.

Tiani et al. [5] reported that the administration of apelin receptor blocker (F13A) effectively decreased 
splanchnic neovascularization and the formation of Porto systemic collateral vessels as well as the expression of proangiogenic factors vascular endothelial growth factor, PLT-derived growth factor, and angiopoietin-2. These findings strongly suggested a possibility of the apelin antagonist (F13A) as a new therapeutic target in terms of both fibrosis and $\mathrm{PH}$. Principe et al. [15] also reported that rats with cirrhosis treated with the apelin receptor antagonist showed decreased hepatic fibrosis and vessel density, improved cardiovascular performance, and renal function and lost ascites. These findings suggest that the apelin-APJ system could be a candidate for a therapeutic target of antifibrosis and antiportal hypertension treatment.

Our present data also found a significant positive correlation between serum apelin level and both AST and ALT, which is similar to the result of Sagiroglu et al. [25], who found that ALT and AST levels were significantly higher in rats injected with apelin intraperitoneally and then exposed to ischemia/reperfusion injury than the control group.

Also, our study found a significant positive correlation between serum apelin and liver fibrosis estimated by the AST/PLT index. These results are in agreement with Farid et al. [26], who analyzed the pattern of apelin expression in different stages of human CLD. In the early stage of hepatic fibrosis (F1 and F2), apelin was almost undetectable as in nonparenchymatous cells, such as sinusoidal endothelial cells/hepatic stellate cells, myofibroblasts, and endothelial cells. With progression of liver fibrosis (F3), apelin-positive cells were located in sinusoidal endothelial cells/ hepatic stellate cells. In cirrhosis (F4), apelinpositive cells shifted to the fibrotic septa and spread as linear staining in the septa and on the proliferated capillary endothelial cells.

\section{Conclusion}

Serum apelin is elevated in patients with cirrhosis and $\mathrm{PH}$, and a positive correlation was found between serum apelin and degree of hepatic fibrosis. Measurement of serum apelin levels can represent a rapid, noninvasive method for the prediction of $\mathrm{PH}$ in cirrhotic patients.

\section{Financial support and sponsorship}

Nil.

\section{Conflicts of interest}

There are no conflicts of interest.

\section{References}

1 Gatta A, Bolognesi M, Merkel C. Vasoactive factors and hemodynamic mechanisms in the pathophysiology of portal hypertension in cirrhosis. Mol Aspects Med 2008; 29:119-129.

2 Altinkaya SÖ, Nergiz S, Küçük M, Yüksel H. Apelin levels in relation with hormonal and metabolic profile in patients with polycystic ovary syndrome. Eur J Obstet Gynecol Reprod Biol 2014; 176:168-172.

3 Kasai A, Shintani N, Kato H, Matsuda S, Gomi F, Haba R, et al. Retardation of retinal vascular development in apelin-deficient mice. Arterioscler Thromb Vasc Biol 2008; 28:1717-1722.

4 Cox CM, D’Agostino SL, Miller MK, Heimark RL, Krieg PA. Apelin, the ligand for the endothelial G-protein-coupled receptor, APJ, is a potent angiogenic factor required for normal vascular development of the frog embryo. Dev Biol 2006; 296:177-189.

5 Tiani C, Garcia-Pras E, Mejias M, de Gottardi A, Berzigotti A, Bosch J, et al. Apelin signaling modulates splanchnic angiogenesis and portosystemic collateral vessel formation in rats with portal hypertension. J Hepatol 2009; 50:296-305.

6 Masri B, Knibiehler B, Audigier Y. Apelin signalling: a promising pathway from cloning to pharmacology. Cell Signal 2005; 17: 415-426.

7 Devic E, Rizzoti K, Bodin S, Knibiehler B, Audigier Y. Amino acid sequence and embryonic expression of MSR/APJ, the mouse homolog of Xenopus Xmsr and human APJ. Mech Dev 1999; 84:199-203.

8 Inui M, Fukui A, Ito $\mathrm{Y}$, Asashima M. Xapelin and Xmsr are required for cardiovascular development in Xenopus laevis. Dev Biol 2006; 298: 188-200.

9 Saint-Geniez M, Masri B, Malecaze F, Knibiehler B, Audigier Y. Expression of the murine MSR/APJ receptor and its ligand apelin is upregulated during formation of the retinal vessels. Mech Dev 2002; 110:183-186.

10 Saint-Geniez M, Argence CB, Knibiehler B, Audigier Y. The MSR/APJ gene encoding the apelin receptor is an early and specific marker of the venous phenotype in the retinal vasculature. Gene Expr Patterns 2003; 3:467-472.

11 Kasai A, Shintani N, Oda M, Kakuda M, Hashimoto $H$, Matsuda T, et al. Apelin is a novel angiogenic factor in retinal endothelial cells. Biochem Biophys Res Commun 2004; 325:395-400.

12 Masri B, Morin N, Cornu M, Knibiehler B, Audigier Y. Apelin (65-77) activates p70 S6 kinase and is mitogenic for umbilicalendothelial cells. FASEB J 2004; 18:1909-1911.

13 Kidoya $\mathrm{H}$, Ueno M, Yamada $\mathrm{Y}$, Mochizuki N, Nakata M, Yano T, et al. Spatial and temporal role of the apelin/APJ system in the caliber size regulation of blood vessels during angiogenesis. EMBO J 2008; 27: 522-534

14 Sorli SC, Le Gonidec S, Knibiehler B, Audigier Y. Apelin is a potent activator of tumour neoangiogenesis. Oncogene 2007; 26 7692-7699.

15 Principe A, Melgar-Lesmes P, Fernandez-Varo G, Ruiz del Arbol L, Ros J, Morales-Ruiz M, et al. The hepatic apelin system: a new therapeutic target for liver disease. Hepatology 2008; 48:1193-1201.

16 Sorli SC, van den Berghe L, Masri B, Knibiehler B, Audigier Y. Therapeutic potential of interfering with apelin signalling. Drug Discov Today 2006; 11:1100-1106.

17 Melgar-Lesmes P, Casals G, Pauta M, Ros J, Reichenbach V, Batallar $\mathrm{R}$, et al. Apelin mediates the induction of profibrogenic genes in human hepatic stellate cells. Endocrinology 2010; 151: 5306-5314.

18 Yokomori H, Oda M, Yoshimura K, Machida S, Kaneko F, Hibi T. Overexpression of apelin receptor (APJ/AGTRL1) on hepatic stellate cells and sinusoidal angiogenesis in human cirrhotic liver. $J$ Gastroenterol 2011; 46:222-231.

19 Bertolani C, Marra F. The role of adipokines in liver fibrosis. Pathophysiology 2008; 15:91-101.

20 Lim YL, Choi E, Jang YO, Cho YZ, Kang YS, Baik SK, et al. Clinical implications of the serum apelin level on portal hypertension and prognosis of liver cirrhosis. Gut Liver 2016; 10:109-116 
21 Garica-Diaz D, Campion J, Milagro FI, Martinez JA. Adiposity dependent apelin gene expression: relationships with oxidative and inflammation markers. Mol Cell Biochem 2007; 305:87-94.

22 Bataller R, Sancho-Bru P, Ginès $\mathrm{P}$, Lora JM, Al-Garawi A, Sole M, et al. Activated human hepatic stellate cells express the renin-angiotensin system and synthesize angiotensin II. Gastroenterology 2003; 125: 117-125.

23 Lindahl $\mathrm{P}$, Johansson BR, Levéen P, Betsholtz C. Pericyte loss and microaneurysm formation in PDGF-B deficient mice. Science 1997; 277: 242-245.
24 El-Mesallamy HO, Hamdy NM, Rizk HH, El-Zayadi AR. Apelin serum level in Egyptian patients with chronic hepatitis C. Mediators Inflamm 2011; 703031:7.

25 Sagiroglu T, Aksoy MB, Sagiroglu G, Tozkir H, Oguz S, Yalta T, et al. Effect of leptin and apelin preconditioning on hepatic ischemia reperfusion injury in rats. Indian J Surg 2014; 76:111-116. ?

26 Farid RM, Abu-Zeid RM, El-Tawil A. Emerging role of adipokine apelin in hepatic remodelling and initiation of carcinogensis in chronic hepatitis C patients. Int J Clin Exp Pathol 2014; 7: 2707-2717. 